\title{
EDUCATIONAL INNOVATION PROJECT: CRITICAL ARCHITECTURE
}

\author{
L. García-Soriano, M. Diodato, V. Cristini, Y. Hernández Navarro, C. Mileto, \\ F. Vegas
}

Universitat Politècnica de València (SPAIN)

\begin{abstract}
The cross-disciplinary skill of critical thinking is essential to all levels of architectural training. However, it has been established that at present students are not always able to make solid architectural critical thinking. This paper presents the development of an action protocol proposed to consciously contribute to exercising this cross-disciplinary skill among students participating in the educational innovation project: "Critical architecture. Development of a methodology to work on the cross-disciplinary skill of critical thinking among architecture students".
\end{abstract}

The research proposed is developed as part of different subjects of the Architecture degree of the UPV Higher Technical School of Architecture: two obligatory 4th-year subjects and an obligatory 5th-year subject. This proposal has also incorporated an elective subject from the Master's in Architecture and two subjects from the Official Master's in Conservation of Architectural Heritage. The educational innovation project therefore covers six different subjects in total: three from the degree (4th and 5th year) (skill level II) and three from the master's (skill level III).

The main aim of the project is to carry out different learning actions (adapted to each of the subjects covered by the project) in order to structure a work methodology designed to improve and develop the cross-disciplinary skill of critical thinking among students at different levels. Work will also be carried out to improve students' awareness of their ability in this skill.

This innovation project is also geared towards improving student learning in the specific curriculum for each subject included in the project. Therefore, if this methodology yields positive results, it could be adapted to other skill levels as yet undeveloped, such as skill level 1 in 2 nd and 3rd year subjects.

Keywords: critical thinking, educational innovation project.

\section{INTRODUCTION}

This educational innovation and research project is being developed within the framework of different subjects from the degree in Architecture of the UPV Higher Technical School of Architecture: "Theory of architecture" and "Architectural Composition", obligatory $4^{\text {th }}$-year subjects, and "Architectural restoration", an obligatory 5th-year subject. This proposal will also include an elective subject from the Master's in architecture: "Restoration of non monumental Historic Architecture" and two subjects from the Official Master's in Conservation of Architectural Heritage, "Theory and History of Conservation" and "Intervention Criteria. From theory to practice". In short, this educational innovation project involves 6 different subjects: 3 at degree level and 3 at master's level.

Subjects on the historical and theoretical components of architecture stimulate and develop the skills linked to critical thinking. Different reading and writing practices are used for this, incorporating a capacity for analysis and visual thinking. The point is not to memorize but to ultimately comprehensively shape the profile of new architects capable of taking on a leading role which is increasingly interdisciplinary, sensitive and conscious.

Theory of architecture forms the basis on which architectural critique is formed. Understanding this system of thinking could help students understand the importance of studying the history and theory of architecture as subjects essential to design work, as they make it possible to develop the critical thinking which will later be applied in architectural composition. Another specific aspect of architectural theory and criticism is the theory and critical analysis of restoration and intervention in the built heritage. This makes it necessary for students to practice and develop critical thinking, first in general terms relating to built (historic or contemporary) architecture to subsequently exercise critical thinking specifically applied to a given field such as architectural restoration.

In the case of the subjects examined in this study, this skill is developed in skill level II for degree subjects and level III in master's subjects. Furthermore, in the case of "Theory and History of Conservation" the 
subject is a monitoring point for critical thinking, cross-disciplinary skill 09 , and as such, it must be evaluated specifically.

The UPV's institutional project offers the following definition for the cross-disciplinary skill of Critical Thinking: "Critical thinking goes beyond the skills of logical analysis as it entails questioning the underlying assumptions in our usual ways of thinking and acting so as to be ready to think and act differently, based on this critical questioning. Critical thinking is the thinking of questions: why are things like this?; why can they not be different?; why do you think they are this way?; etc. Consequently, a person is said to have developed critical thinking insofar as they question things and express an interest in the foundations on which ideas, assessments and judgements, both one's own and those of others, rest". Furthermore, the educational activities linked to the development of this skill are Case studies, Ethical dilemmas, Oral presentations, Forums and debates, Games and simulation, Reports, Readings, Questions, and Projects [1].

\section{METHODOLOGY}

The methodology followed for this research project contemplates the following phases:

- Before starting the protocol of the educational innovation project an in-depth review was carried out of the state of the art of the theoretical framework with respect to the competence of critical thinking [2] [3] [4] [5] [6]. The specific literature of other teaching experiences in the field was also reviewed, highlighting some works on the self-perception of critical thinking [7] and the validation of assessment tools [8]. Studies which develop similar experiences in historical-theoretical subjects were also consulted [9] as well as specific texts focusing on work on the skill of critical thinking through theory texts, which is the central axis of this innovation project proposal, work based on the texts to develop critical thinking, in both oral and written form [10].

- A protocol action was later developed, specifically adapted to each of the subjects included part in this project.

\section{OBJECTIVES}

The general objective of this educational improvement and innovation project is to carry out several learning actions (adapted to each of the subjects examined in the project) in order to structure a work methodology of the critical thinking cross-disciplinary skill and improve this skill among students at different levels. Work will also be carried out to improve students' self-perception of their ability in this skill.

The specific objectives set are:

- To stimulate critical thinking among architecture students, both at degree and master's levels. To do so, specific activities will be prepared to examine the curriculum of each individual subject. However, these will be proposed following a homogeneous general methodology (written exercises for the individual and/or group analysis of texts, oral presentation of exercises, debates).

- To practise the effective communication of students, both oral and written. For this, activities will be carried out to develop both effective communication and critical thinking among students.

- To assess whether students' self-perception of their capacity for critical thinking improves after completing the different activities in the project. Students have a self-perception of their skills which could usually be improved, also improving their self-regulation and providing more satisfactory academic results [11].

\section{ACTION PROTOCOL AND ACTIVITIES}

Taking into account the premises mentioned above in order to attain the specific objectives previously proposed, several specific work activities (reading and analysis of theory texts both individually and in groups, oral presentations, debates...) were designed as part of the subjects covered by the educational improvement project. 
In each subject the type of critical thinking exercise will be adapted to individual work diagrams, so that the first phase of activity design will be specific to each individual subject:

- Design and organization of critical thinking exercises: the different activities to be carried out during the academic year will be designed specifically for working on critical thinking (reading and analysing texts, exhibitions, debates...).

However, a protocol was proposed with a global scheme for all subjects in order to compare and extract both partial and global conclusions. Therefore, the tasks - in chronological order - are as follows:

1 Completing a self-perception test on critical thinking (Pre-test): each subject will include a short self-perception test on critical thinking to identify the starting point for the self-perception of students in this competence. (Timeline: first weeks of the academic year)

2 Developing critical thinking exercises: each teacher will carry out the experimental activities in their group to help develop critical thinking among the students. These activities will be assessed and the students provided with the necessary feedback to ensure that they are learning correctly. An activities plan has been designed to suit individual subjects while following a global work methodology. Thus, the different subjects have focused on different types of exercise:

4th Year. Theory of architecture. Type of exercise: Reading and analysis of texts.

4th Year. Architectural composition. Type of exercise: Case study analysis.

5th Year. Architectural restoration. Type of exercise: Debate.

Master's. Conservation of non monumental historic architecture. Type of exercise: Case study analysis.

Master's. Theory and history of conservation. Analysis of texts and case studies.

Master's. Intervention criteria. Debate, attendance to congresses.

Therefore, different activities have been planned with methodologies which are repeated at both degree and master's level in order to extract preliminary conclusions on the application of these methodologies.

3 One-day presentation of the projects completed: at the end of the subjects and the different completed exercises a session will be held for oral presentations of the work carried out to share the experience with classmates. In parallel, these sessions will also be used to develop the oral expression competences of students.

4 Self-perception test for critical thinking (Post-test): for each subject the self-perception tests on critical thinking carried out at the start of the academic year will be carried out again to assess any possible changes in how students perceived this skill. (Timeline: last week of academic year)

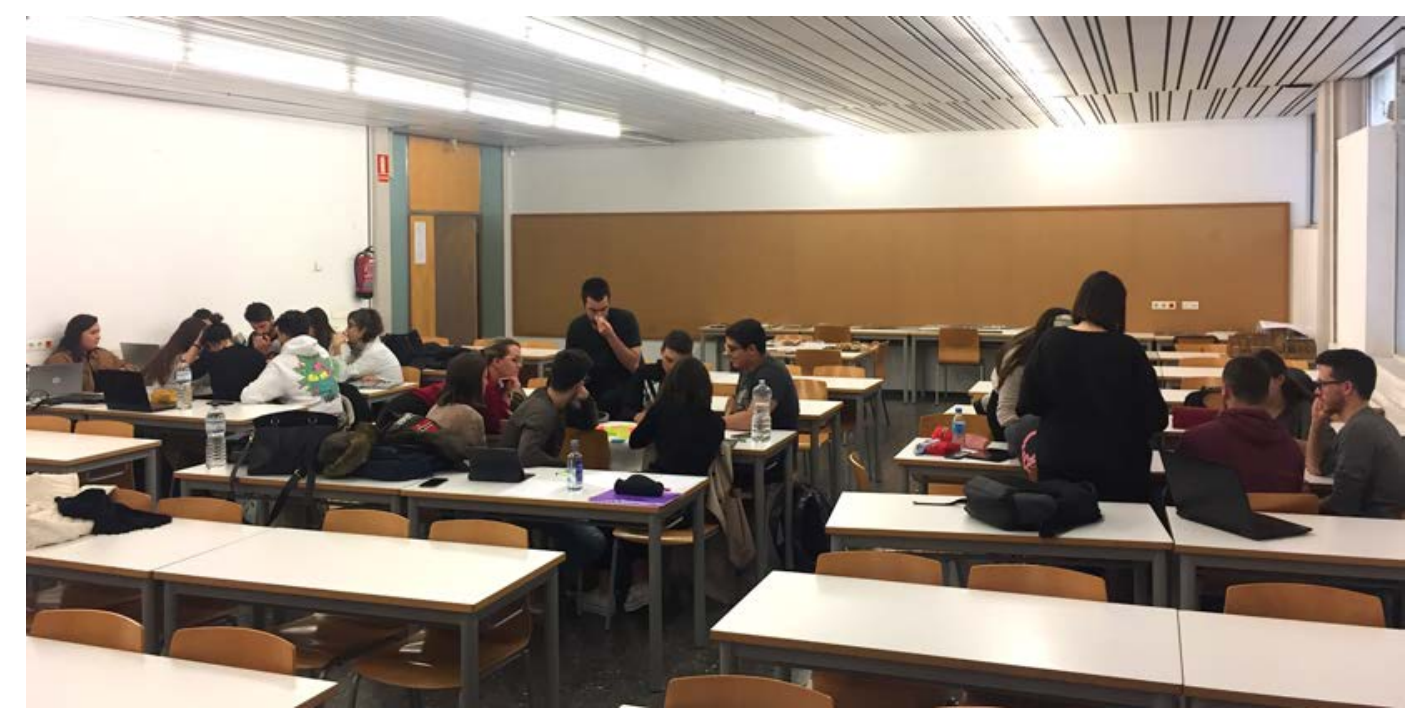

Figure 1. Students in the subject of Architectural Composition working in groups on the critical thinking exercise (case study analysis). 
At the end of the academic year the protocol in place is used to assess the results obtained (positive or improvable):

- Assessment of results obtained: after completing the process the possible improvement of students' command of the skill of critical thinking is assessed based on the evidence obtained from the different exercises completed. The necessary tools (rubrics) will be prepared for this assessment.

It should be stressed that this educational innovation and improvement project is implemented and developed over two academic years (2019-2020 and 2020-2021). That is to say, the first year of the project was implemented this year, as the academic year was viewed as an initial test for the product. Upon completion it will be reviewed and adjusted so that it can be implemented again in the following academic year, incorporating the relevant modifications based on the partial results obtained.

\section{ASSESSMENT TOOLS}

For the assessment phase for results (positive or not) of the project, a series of specific assessment tools have been used to evaluate the skill and students' self-perception of Critical Thinking.

1 Assessment of the cross-disciplinary skill of Critical Thinking: Specific rubrics are developed to assess students' exercises. Work will be based on the institutional rubrics of the UPV, specifically that of "critical thinking" skill level II and III and the rubric of "oral communication and expression", which can be adjusted and modified slightly to suit the specific needs of each exercise.

2 Assessment on students' self-perception of their capacity for critical thinking. A survey is prepared based in the test by Pintrich et al. (1991), a tool which has already been validated and contrasted. Although this test is much broader it incorporates specific items for assessing selfperception of the capacity for critical thinking. Therefore, this test could be well-suited to the project objective as it is a brief questionnaire which can be easily completed by the students.

\section{Cognitive and Metacognitive Strategies: Critical Thinking}

Critical thinking refers to the degree to which students report applying previous knowledge to new situations in order to solve problems, reach decisions, or make critical evaluations with respect to standards of excellence.

Item
38. I often find myself questioning things I hear or read in this course to decide if I find them convincing.
47. When a theory, interpretation, or conclusion is presented in class or in the readings, I try to decide if there is good supporting evidence.
51. I treat the course material as a starting point and try to develop my own ideas about it.
66. I try to play around with ideas of my own related to what I am learning in this course.
71. Whenever I read or hear an assertion or conclusion in this class, I think about possible alternatives.

Figure 2. Extract on critical thinking for the test by Pintrich et al. (1991), used for pre- and post-test assessment.

\section{CONCLUSIONS}

After the partial results obtained following the implementation of the protocol in the first year it will be possible to make any necessary adjustments for the following academic year. The project is currently nearing the end of this first year so it seems premature to put forward conclusions. However, as a preliminary conclusion an improvement is expected in students' critical thinking capacity which should be evaluated through the different evidence obtained from the exercises, with a pre-and post-test methodology allowing teachers to identify any substantial difference between the exercises carried out 
at the start and at the end of the subjects. Furthermore, as the educational innovation project has been designed with a 2-year duration, it will be possible to assess whether the results obtained in 4th year of the degree also contribute during the second year of the project to the activities carried out by 5th-year students. Equally, some 5th-year students will be master's students in the second year of the project and it will be possible to contrast results.

In addition, this project also aims to improve students' learning in the specific content of each subject included in the project. Therefore, if the results of this methodology are positive, both as regards the content of individual subjects and the cross-disciplinary skill of critical thinking, it can be adapted to other skill levels which have not yet been developed, as is the case of skill level I in 2 nd and 3rd year subjects.

\section{ACKNOWLEDGEMENTS}

This research was funded through a UPV Educational Innovation and Improvement Project (PIME) in the modality of "projects for curricular innovation in subjects".

\section{REFERENCES}

[1] http://www.upv.es/contenidos/COMPTRAN/. Proyecto institucional UPV de competencias transversales.

[2] L. da Silva Almeida, A. Helena Rodrigues Franco, Critical thinking: Its relevance for education in a shifting society. University of Minho, Portugal.

[3] E. R. Lai, Critical Thinking: A Literature Review. Research Report. June 2011.

[4] R. Paul, L. Elde, La mini-guía para el Pensamiento crítico. Conceptos y herramientas. Fundación para el Pensamiento Crítico. www.criticalthinking.org

[5] P. Facione, Pensamiento Crítico: ¿Qué es y por qué es importante?.

[6] R. Paul, L. Elde, Estándares de Competencia para el Pensamiento Crítico. Estándares, Principios, Desempeño. Indicadores y Resultados. Con una Rúbrica Maestra en el Pensamiento Crítico. Fundación para el Pensamiento Crítico. www.criticalthinking.org

[7] L. Basco Prado, N. Rodríguez Avila, M. Puig Llobet, M.T. Lluch Canut, S. Fariñas Rodríguez, M.A. Giménez Lajara, "Escala de Autopercepción del Pensamiento Crítico en Alumnos de EnfermeríaCritical Thinking Self-perception scale in Nursing Students". III Congreso Internacional sobre Aprendizaje, Innovación y Competitividad (CINAIC 2015). Octubre 14-16, 2015, Madrid.

[8] K. Curione, J.A. Huertas, "Revisión del MSLQ: veinticinco años de evaluación motivacional" [en línea]. Revista de Psicología, 12(24). 2016.

[9] A. Gual Gual, E.A. Burgos Ramírez, S. Cuenca Almenar, "Pensamiento crítico en la construcción del conocimiento en la asignatura de Historia de la Ciencia y la Tecnología-Critical Thinking in the construction of knowledge in History of Science and Technology course". II Congreso Internacional sobre Aprendizaje, Innovación y Competitividad (CINAIC 2013). Noviembre 6-8, 2013, Madrid.

[10] C. Adriana, L. González, "Criterios para el desarrollo del pensamiento crítico a través de textos literarios". Revista Letras, ISSN 0459-1283, № 91, 2014.

[11] P.R. Pintrich, D.A.F. Smith, T. García, W.J. McKeachie, A manual for the use of the motivated strategies questionnaire (MSLQ). Ann Arbor, Ml: University of Michigan, National Center for Research to Improve Postsecondary Teaching and Learning. 1991. 